Bu makaleye atıfta bulunmak için/To cite this article:

BURNAZ, E. KAROĞLU, E. (2021). Destinasyon Rekabetçiliği ile Doğrudan Yabancı Yatırımlar

Arasındaki İlişki: Panel Veri Analizi. Atatürk Üniversitesi Sosyal Bilimler Enstitüsü Dergisi, 25 (4),

1520-1536.

\title{
Destinasyon Rekabetçiliği ile Doğrudan Yabancı Yatırımlar Arasındaki İlişki: Panel Veri Analizi*
}

\author{
Ersin BURNAZ ${ }^{(* *)}$ \\ Ertuğrul KAROĞLU ${ }^{(* * *)}$
}

Öz: Ülkeler arasındaki önemli rekabet konularından birisi dünya turizminden daha yüksek oranda pay almak ve turizm yatırımlarından azami düzeyde faydalanmaktır. Bu çalışmada ülkelerin turizm alanındaki rekabetçi güçlerinin, yabancl yatırım çekme konusunda ne derece etkili olduğunun Dunning'in OLI paradigmast çerçevesinde tespiti amaçlanmıștır. Bir ülkenin turizm alanındaki rekabet gücünü belirlemek için Dünya Ekonomik Forumu tarafindan oluşturulan "Turizm ve Seyahat Rekabetçilik Endeksi (TSRE)"nin 4 ana kriteri (Çevresel Faktörler, Turizm Politikalarının ve Koşullarının Etkinleştirilmesi, Altyapı, Doğal ve Kültürel Kaynaklar), OLI paradigması kapsamında kavramsallaştırılan lokasyona özgü faktörler olarak ele alınarak bağımsız değişkenler belirlenmiştir. Bă̆ımlı değişken olarak belirlenen doğrudan yabancı yatırımlar (DYY) verilerine ise UNCTAD veri tabanı kullanılarak erişilmiştir. 8 yıl ve 114 ülkeyi kapsayan zaman uzanıml veriler panel regresyon analizi kullanılarak test edilmiștir. Elde edilen bulgular, destinasyon rekabetçiliğinin altyap ile doğal ve kültürel kaynaklar değişkenlerinin DYY girişleri üzerinde anlamlı ve pozitif yönlü etkilere sahip olduğunu ortaya koymaktadır.

Anahtar Kelimeler: Destinasyon rekabetçiliği, Doğrudan Yabancı Yatırımlar (DYY), Dünya Ekonomik Forumu Turizm ve Seyahat Rekabetçilik Endeksi (TSRE), panel veri analizi.

\section{The Relationship Between Destination Competitiveness and Foreign Direct Investments: Panel Data Analysis}

Abstract: One of the important competition issues between countries is to get a share from world tourism at a higher rate and to benefit from tourism investments at the maximum level. In this study, it is aimed to determine how effective the competitive forces of countries in the field of tourism are in attracting foreign investment within the framework of Dunning's OLI paradigm. In order to determine the competitiveness of a country in the field of tourism, the 4 main criteria of the "Tourism and Travel

*) Bu çalışma 20-21 Nisan 2018 tarihleri arasında İskenderun Teknik Üniversitesi bünyesinde düzenlenen VII. Ulusal III. Uluslararası Doğu Akdeniz Turizm Sempozyumu'nda sunulmuş bildirinin bir kısmının genişletilmesiyle üretilmiştir.

**) Dr. Öğr. Üyesi, Trabzon Üniversitesi Beşikdüzü Meslek Yüksekokulu Pazarlama ve Reklamc1lik Bölümü (e-posta: ersinburnaz@trabzon.edu.tr) (D) ORCID ID. https://orcid.org/0000-0002-2827-4236

${ }^{* * *}{ }^{*}$ Dr. Öğr. Üyesi, Trabzon Üniversitesi Beşikdüzü Meslek Yüksekokulu Yönetim ve Organizasyon Bölümü (e-posta: ekaroglu@trabzon.edu.tr) (D) ORCID ID. https://orcid.org/0000-0001-9746-4693

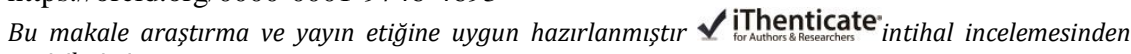
geçirilmiştir. 
Competitiveness Index (TTCI)" created by the World Economic Forum were considered as location-specific factors conceptualized within the OLI paradigm and independent variables were determined. Direct foreign capital investments that are the dependent variable of the present study were extracted from the UNCTAD database. Data covering 8 years and 114 countries were tested using panel regression analysis. The findings reveal that the infrastructure and natural and cultural resources variables of destination competitiveness have significant and positive effects on FDI inflows.

Keywords: Destination Competitiveness, Foreign Direct Investments (FDI), World Economic Forum Travel and Tourism Competitiveness Index (TTCI), Panel Data Analysis.

Makale Geliş Tarihi: 21.03.2021

Makale Kabul Tarihi: 25.12.2021

DOI: 10.53487/ataunisosbil.900702

\section{Giriş}

Son yıllarda ülkeler, gelişmişlik göstergelerinden biri olan doğrudan yabancı yatırımları (DYY) daha fazla çekmek için gayret göstermektedirler. Yabancı yatırım, "yatırılabilir kaynakların kişi ve kuruluşlar tarafından bir başka ülkeye taşınması" olarak tanımlanırken (DPT, 2000: 1) DDY ise "menkul kıymet alımlarını ifade eden portföy yatıımları dışında kalan, yabancı yatııımıların tek başlarına veya yerli yatırımcılarla ortaklık kurarak gerçekleştirdikleri yatırımlardır" şeklinde ifade edilmektedir (Karagöz, 2007: 930). Ekonomik Kalkınma ve İşbirliği Örgütü (OECD) ise doğrudan yabancı yatırımı; "bir ekonomide yerleşik bir birim tarafından (doğrudan yatırımcı) başka ülkede yerleşik olan bir teşebbüste kalıcı bir ekonomik bağ sağlamak amacıyla yapılan uluslararası yatırım kategorisi" şeklinde tanımlamaktadır (Özcan ve Arı, 2010: $67)$.

Özellikle son dönemlerde devletlerin liberal ekonomik politikalar güttükleri, bir başka ifade ile daha liberal yasal düzenlemeler meydana getirerek DYY çekme konusunda bir çaba içerisinde oldukları bilinmektedir. Örneğin 2001 yılında 71 ülke DYY rejimlerini düzenleme konusunda 208 yasal değişiklik yapmış bu ülkelerden 194'ü de daha yüksek oranda DYY çekmiştir (Subbarao, 2008: 107). Daha fazla DYY çekmek için ülkeler, sermaye hareketleri üzerindeki kontrolleri kaldırmak, ulaşım ve haberleşme altyapılarını iyileştirmek, vergi oranlarını ve döviz kuru politikalarını düzenlemek gibi çok sayıda düzenlemeyi hayata geçirmiş̧ir (Kar ve Tatlıs̈z, 2008). Özellikle yerel finansal kaynakların sınırlı olduğu ülkelerde yabancı yatırımcılar işletmelerin finansal ihtiyaçlarının karşılanmasında çok önemli rol oynamaktadır (Leuz ve diğerleri, 2010: 3280).

DYY'nin küresel ekonomilerdeki önemi her geçen gün artarken yerel ekonomilere önemli miktarlarda döviz girdisi sağlayan sektörlerden birisinin de turizm sektörü olduğu bilinmektedir (Ravinthirakumaran vd, 2015: 236). Bu noktada alanyazında DYY girişlerinin turizm sektörü için de ayrıcalıklı bir öneme sahip olduğu (Contractor ve Kundu, 1995; Kundu ve Contractor, 1999) belirtilmekte ve DYY'yi etkileyen faktörler olarak destinasyona özel faktörlerin öneminin altı çizilmektedir (Dobrivojevic, 2013). Konuyu böyle bir bakış açısıyla ele alan öncül çalışmalarda, turizm sektörü açısından, bir yerin veya bölgenin (destinasyonun) "rekabetçi yatırım destinasyonu" imajını elde etmesinin başarıı 
bir şekilde DYY çekebilmesi için önemli olduğu ileri sürülmektedir. Dolayısıyla, ülkelerin turizm sektörü için DYY çekebilmeleri, rekabetçi yatırım destinasyonu imajına sahip olmalarına bağlı olduğu iddia edilebilmektedir (Metaxas, 2010: 238).

Ülkeler arasındaki DYY hareketlerini açıklama iddiasında olan öncül kuramlar (Dunning, 1980; 1988; 2000; 2001; Mathews, 2002; 2006; Johanson ve Wiedersheim Paul, 1975; Johanson ve Vahlne, 1977) dikkate alındığında destinasyon rekabetçiliği ile DYY girişleri arasındaki ilişkinin ev sahibi ülkelerin sahip olduğu lokasyona özgü avantajları ile ilişkilendirilmesinin yerinde olacağı düşünülmektedir. Böyle bir bakış açısı, Dunning (1980; 1988; 2000; 2001) tarafından ortaya konulan Eklektik Paradigma çerçevesinde düşünüldüğünde daha iyi anlaşılmaktadır. Eklektik Paradigma bakış açısı ile düşünüldüğünde destinasyon rekabetçiliği faktörlerinin yabancı yatırımcıları DYY noktasında teşvik eden birer avantaj olarak kabul edilip edilemeyeceği ve DYY girişlerinin bu avantajlara bağlı olarak nasıl bir değişim göstereceği soruları akla gelmektedir.

Bu kavramsal açıklamalardan hareketle bu çalışmada Dünya Ekonomik Forumu'nun iki yılda bir açıklamış olduğu TSRE faktörleri birer lokasyona özgü avantaj olarak kabul edilerek bu avantajların, ülkelere gelen DYY akışları üzerindeki etkilerini ortaya koymak amaçlanmıştır.

Böyle bir araştırma sorusunun alanyazına kuramsal ve uygulamacı açılarından katkı sağlayacağı düşünülmektedir. Bu noktada çalışma Dunnig tarafından ortaya konulan ve alanyazında geniş ölçüde kabul gören Eklektik Paradigmanın, turizm sektöründe, turizm rekabetçiliğini açıklamaya yönelik faktörleri kuramın temel varsayımlarından biri olan lokasyona özgü faktörler olarak ele alan bir bakış açısıyla sınanmasına olanak tanımaktadır. Uygulamacı açıdan düşünüldüğünde ise ülkelerin DYY girişlerini arttırma konusundaki dikkate alınması gereken faktörlerin destinasyon rekabetçiliği açısından ortaya konulmasının politika yapıcılar açısından önemli bakış açıları sağlayacağı öne sürülebilir.

Çalışmanın ilk bölümünde, ilgili yazın gözden geçirilerek kavramsal bir çerçeve oluşturulmakta ve araştırma hipotezleri geliştirilerek kullanılan model açıklanmaktadır. Ardından araştırmanın tasarımı ve bulguları sunulmaktadır. Daha sonra sonuç ve tartı̧̧ma bölümüyle çalışma sonlandırılmaktadır.

\section{Kavramsal Çerçeve}

Uluslararası işletmecilik alanyazınında DYY'i açıklamaya çalışan birçok alternatif uluslararasılaşma kuramının olduğu bilinmektedir. ${ }^{1}$ Bu kuramlardan en bilinenleri Dunning' in Eklektik Paradigması (Dunning, 1980; 1988; 2000; 2001), Mathews'in LLL Modeli (Mathews, 2002; 2006) ve Uppsala Modeli'dir (Johanson ve Wiedersheim Paul, 1975; Johanson ve Vahlne, 1977). ${ }^{2}$

\footnotetext{
${ }^{1}$ Bu konuda ayrıntılı bir değerlendirme için Surdu vd. (2018) tarafından yapılan çalışma incelenebilir.

${ }^{2}$ Gelişmekte olan bir ekonomi olarak değerlendirilen Türkiye'den ülke dışına çıkan DYY'lerin giriş stratejileri üzerindeki etkisini üç kuramı bir arada ele alarak araştıran ve kuramlardan hangisinin bağlamı daha iyi açıkladığı noktasında İlhan-Nas vd. (2020) tarafından yapılan çalışma incelenebilir.
} 
Mathews'un LLL Modeli, gelişmekte olan ülke işletmelerinin uluslararasılaşma süreçlerini ve stratejilerini daha iyi açıkladığını iddia ederken (Mathews, 2002; 2006) Uppsala Modeli ise ülkeler arasındaki kurumsal mesafe, yolsuzluk mesafesi, kültürel mesafe ve coğrafi mesafeye odaklanmıştır (Johanson ve Wiedersheim Paul, 1975; Johanson ve Vahlne, 1977). OLI Paradigmas1 olarak da bilinen Dunning'in Eklektik Paradigması ise DYY davranışını belirleyen unsurların sahiplik (ownership), konum (location) ve içselleștirme (internalization) avantajları olduğunu ileri sürmektedir (Dunning, 1980; 1988; 2000 ; 2001). Sahiplik avantajı, rakiplerin sahip olmadığı varlıklara işletmenin ne ölçüde sahip olduğunu ifade etmektedir. İçselleştirme avantajı ise, işletmenin sahip olduğu varlıkları, başka işletmelere devretmek, kiralamak veya satmak yerine, bahsi geçen bu varlıkları içselleştirerek kendi uhdesinde bulundurması ve böylece avantaj elde etmesini ifade etmektedir. Son olarak konum avantaj1 yatırımcı ülkenin kaynakları yerine yatırım yapılan ülkenin kaynaklarının sağladığı avantajın altını çizmektedir (Dunning, 1980: 9; Dunning, 2000: 164165). Ayrıca Eklektik Paradigma gelişmiş ülkelerden gelişmekte olan ülkelere doğru olan DYY akımını açıklamada kullanılan kuramlardan biri olarak bilinmektedir (Tatoglu ve Glaister, 1998a; Filatotchev vd., 2007; Surdu vd., 2018: 348).

Ülkelere giden DYY'leri etkileyen etmenler bu alanda çalışan pek çok araştırmac1 için ilgi odağ1 olmuştur (Singh ve Jun, 1995; Bevan ve Estrin, 2000; Busse ve Hefeker, 2005; Candemir, 2009; Karoğlu, 2018). Bu çalışmanın kapsamını oluşturan DYY hareketleri incelendiğinde süreç içerisinde DYY stok ve akımlarının yıllar içerisinde arttığı görülmektedir. Küreselleşme dönemi öncesinde gelişmiş ülkelerden gelişmekte olan ülkelere doğru çok daha fazla DYY akımı söz konusu olurken (www.unctad.org), küreselleşmeyle birlikte gelişmekte olan ülke kökenli DYY, toplam DYY hacmi içerisinde kayda değer bir orana sahip olmuştur. $\mathrm{Bu}$ süreç öncül yazında konuyla ilgili yapılan araştırmalarda da net bir şekilde görülmektedir (İlhan-Nas vd., 2020: 593). Ev sahibi ülkeye giren DYY'ler gitmiş olduğu sektörler bağlamında değerlendirilmeye tabi tutulduğunda özellikle 1990'l1 yıllardan sonra meydana gelen değişiklikler göze çarpmaktadır. 1980'li yıllara kadar ev sahibi ülkeye giren DYY'lerden daha çok imalat sektörünün faydalandığı bilinirken (Kepenek ve Yentürk, 2000) takip eden yıllarda hizmet sektöründe de meydana gelen gelişmelere paralel olarak bu dengenin turizm sektörünü de içerisinde barındıran hizmet sektörü lehine değiştiği görülmektedir (Aykut ve Sayek, 2007: 36).

Turizm sektörünün, özellikle 2000'li yılların sonrasında yaşanılan sarsıntılı dönemlere (terörist saldırılar, siyasi krizler, doğal afetler) rağmen GSYİH artışına doğrudan katkısı olduğu, istihdamı artırdığı bilinmektedir (WTTC, 2018). Ayrıca aynı dönemde ülkelere giden turist sayısında artışlar meydana gelmiştir. Tüm bunlara ek olarak 2030 yılı öngörüsünde ise hem turist sayısında artış (1,8 milyar kişiye ulaşması beklenmekte) hem de gelişmekte olan ülkelerin pazar paylarının artmas1 (\%45'den, \%54'e) beklenmektedir (UNWTO, 2017).

Bahsedilen öncül yazında konuyla ilgili önemli açılımlar sağlanmakla birlikte DYY ile etkileri üzerinde tam bir fikir birliğinin oluştuğu söylenemez. Hem teorik hem de ampirik olarak yapılan çalışmalar sonucunda, alanyazın yabancı 
sermayenin, yatırım yapılan ülkeye olumlu etkilerinin yanı sıra bazı durumlarda olumsuz etkilerinin olduğunu da ileri sürmektedir (Bahar, 2010: 28; Afşar, 2004: 86). Ancak DYY'nin ülke ekonomilerine olumlu etkileri olduğunu ileri süren çalışmalar da mevcuttur (Subbarao, 2008; Koçtürk ve Eker, 2012). Örneğin Subbarao (2008: 107) DYY'nin ekonomik gelişme üzerinde pozitif etkisi olduğunu, yeni iş imkânları yarattığını, üretimi, yerel piyasalardaki rekabeti ve ihracatı artırdığını iddia etmektedir.

Sektörel anlamda değerlendirme yapıldığında, turizm sektörü ile DYY arasındaki ilişki de araştırmacıların ilgilerini çekmektedir (Contractor ve Kundu, 1995; Kundu ve Contractor, 1999; Metaxas, 2010; Salleh vd., 2011). Tang ve arkadaşları (2007:37) Çin turizm sektörü üzerinde yapmış oldukları çalışmada DYY'nin turizm sektörünün büyümesinde önemli bir role sahip olduğunu ortaya koymuşlardır. Fauzel ve arkadaşları (2017) ise yapmış oldukları çalışmada turizm DYY'sinin ekonomik büyümeye katkı sağladığını ileri sürmektedirler.

Tüm bu bakış açıları ile değerlendirme yapıldığında ise turizm sektörünün büyüyen gücünün hem parasal anlamda hem de potansiyel anlamda yatırımcıların dikkatini çekiyor olması doğaldır. Yıllar içerisinde turizm sektörü için gelen DYY artmaktadır (Rodriguez, 2002; Salleh vd., 2011: 252). Ülkelere bu noktada düşen en büyük görev yatırımcıları ikna ederek daha fazla DYY'yi kendi ülkelerine çekmektir. Bu bağlamda bir yerin başarılı bir şekilde DYY çekebilmesi için, "rekabetçi yatırım destinasyonu" imajını elde etmesi gerekmektedir (Metaxas, 2010: 238).

Her ne kadar turizm sektörünün yapısı gereği ekonominin diğer sektörlerinden farklı olarak, turizme gelen DYY'ye ilişkin doğru ve gerçekçi verilere ulaşmak pek mümkün olmasa da (Bahar, 2010: 30; Endo, 2006: 600) DYY ile turizm sektörünün büyümesi arasında anlamlı ilişki bulmuş olan çalışmalar da vardır (Salleh vd., 2011: 251; Peric ve Radic, 2015: 425).

Bir ülkenin turizm alanındaki rekabetçi gücünü belirleyen unsurlar, Dünya Ekonomik Forumu'nun yayınladığı TSRE'nin 4 ana kriteri (Çevresel Faktörler, Turizm Politikalarının ve Koşullarının Etkinleştirilmesi, Altyapı, Doğal ve Kültürel Kaynaklar) olarak düşünülebilir (UNWTO, 2017). Çalışmanın kavramsal çerçevesi ve temel iddiası içerisinde düşünüldüğünde bu faktörlerin OLI paradigması kapsamında tanımlanan birer lokasyona özgü avantaj sağlayacağı ve bu avantajları değerlendirme motivasyonunun yabanc1 yatırımcıların DYY kararlarını etkileyerek dönüşüm içerisinde ülkeye giren DYY hacmini arttıracağı varsayılmaktadır.

Bu varsayım OLI paradigması çerçevesinde değerlendirildiğinde işletmelerin yurt dışına yatırım yapmalarının sebeplerinden birisinin de kendi ülkelerinde elde edebilecekleri kaynaklardan daha yüksek kalitede olan kaynakları, daha düşük maliyetlerle elde edebilme olasılıkları olduğu kabul edilmektedir. Kaynak arayanların üç ana türü vardır. İlki fiziksel kaynakları arayan işletmelerdir. Turizm gibi hizmet faaliyetlerinde konuma bağlı kaynaklar önem arz etmektedir. İkinci grup ise kaynak olarak ucuz ve iyi motive edilmiş vasıfsız veya yarı vasıflı işgörenlerden oluşmaktadır. Üçüncü tür kaynak arayan DYY'ler ise teknolojik yetenek, yönetim veya pazarlama uzmanlığı ve organizasyon becerileri gibi 
işletmenin kendi bünyesine katma istediğidir (Dunning ve Lundan, 2008: 68-69). Tatoglu ve Glaister (1998b: 137) ayrıca Erdal ve Tatoğlu (2002: 23) ise bir ülkeye yatırım yapılmasının yatırım yapan işletme açısından cazip olmasını iki unsur ile açıklamışlardır. Bunlardan ilki doğal kaynaklar, işgücü piyasası ve pazarlara yakınlık olarak değerlendirilirken ikincisi ise yatırım yapılan ülkenin politik, ekonomik, yasal ve altyapı gibi birçok çevresel değişkendir. Bu bağlamda yatırım yapılan ülkedeki kurumsal yapının, yabancı işletmenin yatırım kararını dolayısıyla DYY'yi etkileyeceği ileri sürülmektedir (Dunning ve Lundan, 2008: 137-140). Bu noktada Dünya Ekonomik Forumu yayınlamış olduğu TSRE'nin boyutlarını oluşturan

$\mathrm{H}_{1}$ : Turizm rekabetçiliği faktörleri, DYY girişleri üzerinde anlamlı ve pozitif yönlü bir etkiye sahiptir.

Bilindiği gibi Dünya Ekonomik Forumu'nun yayınlamış olduğu “TSRE'nin dört ana kriterinden biri çevresel faktörlerdir. İş çevresi, emniyet ve güvenlik, sağlık ve hijyen, insan kaynakları ve işgücü piyasası, bilgi ve iletişim teknolojilerine hazır olma gibi alt başlıklar, çevresel faktörler kriterini oluşturmaktadır (WEF, 2019).

Alanyazın incelendiğinde, çevresel faktörler boyutunu temsil eden unsurlar ile DYY arasında ilişki üzerine akademik çalışmalar yapıldığı dikkat çekmektedir (Dunning ve Narula, 2004; Cheng, 2006; Tomohara, 2016). Örneğin; Cheng (2006) DYY ile işgücü maliyetleri arasındaki ilişkinin önemsiz olduğu bulgusuna ulaşmıştır. Ussi ve Wei (2011) ise yapmış oldukları çalışmalarında hem işgücü hem de yatırım maliyetlerinin Zanzibar'daki otel yatırımcılarının yatırım kararları üzerinde önemli bir etkisinin olmadığı sonucuna ulaşmışlardır. Diğer taraftan yüksek işgücü maliyetlerinin DYY akışı üzerinde negatif etkisinin olduğu bir başka deyişle yüksek işgücü maliyetlerinin DYY akışını engellediği iddia edilmektedir (Dunning ve Narula, 2004). Ayrıca yatırım maliyetlerinin DYY akışı üzerinde negatif etkisinin olduğu iddia edilmektedir (UNCTAD, 2006). Özetlenen çalışmaların farklılaşan bulgular ürettiği görülmekle birlikte, OLI paradigmasının temel varsayımları çerçevesinde değerlendirildiğinde, çevresel faktörlere yönelik uygulamaların yabancı yatırımcılar açısından konuma özgü birer avantaj olarak algılanacağı ve dönüşüm içerisinde ülkeye giren DYY hacmi üzerinde olumlu etkiye sahip olacağı öne sürülebilir. Bu varsayımlar ışığında aşağıdaki hipotez geliştirilebilmektedir.

$\mathrm{H}_{1 a}$ : Çevresel faktörler, DYY girişleri üzerinde anlamlı ve pozitif yönlü bir etkiye sahiptir.

TSRE'nin kriterlerinden birisi de turizm politikalarının ve koşullarının etkinleştirilmesidir. Bu noktada birçok ülke, ulusal turizm politikalarının turizmin gelişmesi noktasında anahtar rol oynadığını ileri sürmektedirler (Fayos-Sola ve Pedro Bueno, 2001). Tang ve arkadaşları da (2007:37) Çin bağlamında yapmış oldukları çalışmalarında turizm gelişim politikasının daha fazla DYY akımını sağlayabileceğini iddia etmektedirler. Japonya bağlamını ortaya koymuş olan bir başka çalışmada da ulusal turizm politikalarının geliştirilmesinin ve bu politikaların eşgüdümlemesinin DYY üzerinde pozitif etkisi olduğu iddia edilmektedir (Tomohara, 2016: 440). 
Dünyaya açık olmak, turizm ve seyahat politikaları ve düzenlemeleri ana kriterinin alt başlığıdır. Çin bağlamını ortaya koyan öncül çalışmalar, dünyaya açık olmanın DYY akışı üzerinde anlamlı ve pozitif etkisi olduğunu ortaya koymaktadır (Dees, 1998). Sonraki yıllarda yapılmış olan çalışmalar da Dees'in bulgularını teyit edici niteliktedir. Örneğin Ussi ve Wei (2011) yapmış oldukları çalışmada dünyaya açıklık ile DYY arasında pozitif yönlü ve istatistiksel olarak anlamlı bir ilişki tespit etmişlerdir.

Turizm politikalarının DYY üzerindeki etkisi bakımından düşünüldüğünde kurumsal çevrenin durumunun DYY üzerinde etkisi olduğunu (Di Maggio ve Powell, 1983; Scott, 1995) öne süren yazın da açıklayıcı bir çerçeve sunmaktadır. Örneğin, Rodrick ve arkadaşları yaptıkları çalışmada (2004) ekonomik gelişmeyi etkileyen üç unsuru karşılaştırmışlardır. Bunlar coğrafi ölçüler (iklim, doğal kaynaklar ve taşıma maliyetleri gibi), ekonomik açıklık ve uluslararası ticaretin rolü ve son olarak da kurumların rolüdür (mülkiyet hakları, hukukun üstünlügü̈ ve sosyal altyapı gibi). Bu çalışma sonucunda kurumların rolünün diğer unsurlara göre daha baskın olduğu sonucuna ulaşmışlardır. Bu bağlamda yatırım yapılan ülkedeki kurumsal yapının, yabancı işletmenin yatırım kararını dolayısıyla DYY'yi etkileyeceği ileri sürülmektedir (Dunning ve Lundan, 2008: 137-140). Kurumsal yapı ülkelerin DYY konusundaki rekabetçiliklerini ortaya koyan Dünya Ekonomik Forumu tarafindan yayımlanan Küresel Rekabet Gücü Raporunun (www.weforum.org) da temel göstergelerinden biridir. Söz konusu kurumsal faktörlerin yatırımcı işletmeler için önemli konuma özgü avantajlar sağlayabileceği veya kısıtlamaları yönetme noktasında kullanışlı olabileceği düşünülerek turizm politikalarının ve koşullarının etkinleştirilmesi ile DYY arasında anlamlı bir ilişki olduğu ifade edilebilir.

$\mathrm{H}_{\mathrm{b}}$ : Turizm politikalarının ve koşullarının etkinleştirilmesi, DYY girişleri üzerinde anlamlı ve pozitif yönlü bir etkiye sahiptir.

TSRE'nin 4 ana kriterinden bir diğeri de altyapıdır. Bir ülkenin fiziksel altyapısı sadece ekonomik kalkınma açısından değil, aynı zamanda o ülkede bulunan işletmelerin başarılı bir şekilde çalışma becerilerini de önemli oranda etkilediği ileri sürülmektedir (Asiedu, 2003).

Turizm ile DYY arasındaki ilişki noktasında değerlendirme yapıldığında ise altyapı kullanılabilirliği ne kadar yüksekse altyapı maliyetleri o kadar düşük olmakta ve ev sahibi ülkenin doğrudan yabancı yatırımları çekebilme kabiliyeti de o kadar yüksek olmaktadır (Cheng, 2006). Hatta bu noktada özellikle gelişmekte olan ekonomilere, ekonomik gelişim için uygun olan kaynakları daha iyi altyapı oluşturmak için tahsis edilmesi önerilmektedir (Endo, 2006: 613). Yapılan görgül çalışmalar da bu iddiayı teyit eder niteliktedir. Örneğin Cheng ve Kwan (2000) Japon yatırımcıların Çin'e yaptıkları DYY üzerinde çalışmış ve altyapı maliyetleri ve kalitesinin Çin'e gelen DYY akışını etkileyen oldukça önemli bir faktör olduğu sonucuna ulaşmışlardır.

Bir ülkenin altyapı durumu ülkenin turizm sektörü açısından önemli bir faktör olarak karşımıza çıkmaktadır. Daha spesifik olarak elektrik ve su tedariki, yollar/otoyollar, havayolu imkanları, gibi altyapıyı oluşturan diğer faktörler de turizm sektörüne gelen DYY'de etkili olduğu iddia edilmektedir (Endo, 2006). 
Bir ülkenin turizm sektörüne gelen DYY'ler seçkin oteller, ulaşım imkanları ve turizm cazibe merkezleri (tema parklar vb.) gibi turizm altyapısının gelişmesine öncülük ettiği ve bu durumun da turizm aktivitelerini artırdığı ileri sürülmektedir (Tang vd. 2007: 27).

Karşıt olarak değerlendirme yapıldığında ise farklı bulgular elde etmiş olan çalışmaların varlığından söz edilebilir. Örneğin; çalışmanın aksine, Ussi and Wei (2011)'in Tanzanya'nın Zanzibar Adasında yaptıkları çalışmada, altyapı ile DYY arasında tam anlamıyla bir ilişki tespit edememişlerdir. Özellikle İtalyan firmalarının faaliyet gösterdiği Zanzibar'daki çok sayıda uluslararası otelin düşük altyapı imkânlarına rağmen turizm potansiyelini tercih ettikleri görülmektedir. $\mathrm{Bu}$ işletmeler risk alarak bu yatırımları yapmışlardır.

Dolayısıyla bahsedilen alanyazından ve ev sahibi ülkelerin altyapı olanaklarını önemli konuma özgü faktörler (Dunnig) olarak değerlendirilebileceği yönündeki kuramsal varsayımlardan hareketle bir ülkenin altyapısı ile almış olduğu DYY arasında ilişki olduğu söylenebilir.

$\mathrm{H}_{1 \mathrm{c}}$ : Altyapı, DYY girişleri üzerinde anlamlı ve pozitif yönlü bir etkiye sahiptir.

TSRE'nin 4 ana kriterinden bir diğeri ise doğal ve kültürel kaynaklardır. Bir ülkede bulunan doğal kaynakların fazlalığının o ülkeye giren DYY artırdığı iddia edilmektedir (Morisset, 2000).

Konu ile ilgili öncül çalışmaların ampirik bulgularının da aynı doğrultuda olduğu bilinmektedir. Örneğin Ussi ve Wei (2011)'in Tanzanya bağlamını ele alan çalışmalarında farklı doğal kaynakların kullanılabilirliği, yabancı turizm yatırımcılarını Zanzibar Adası'na çektiğini iddia etmektedirler. Ayrıca Morrisset (2000) DYY akışı ile ilgili ülkedeki doğal kaynakların toplam değeri arasında yüksek bir korelasyon olduğunu ileri sürmektedir. Ek olarak turizm sektörüne yönelik DYY, doğal ve kültürel kaynaklara ve bunlarla ilgili olanaklara sahip yerleri tercih etmektedir (Dunning, 1993). Karşıt olarak bir değerlendirme yapıldığında ise Endo (2006: 613) bir ülkenin doğal kaynaklara sahip olmasının potansiyel yatırımcılar ve turistler için cazibe merkezi olacağı anlamına gelmediğini ifade etmiş̧tir.

Farklılaşan görüşlere rağmen, çalışmanın kuramsal çerçevesi bağlamında ev sahibi ülkenin sahip olduğu doğal ve kültürel kaynakların turizm sektörü açıssından önemli konuma özgü avantajlar sağlayarak DYY girişleri üzerinde olumlu etkiye sahip olacağı varsayılmaktadır. Bu varsayım ışığında geliştirilen hipotez aşağıdaki gibidir.

$\mathrm{H}_{1 \mathrm{~d}}$ : Doğal ve kültürel kaynaklar, DYY girişleri üzerinde anlamlı ve pozitif yönlü bir etkiye sahiptir.

\section{Metodoloji}

A. Örneklem ve Ölçme

Ülkeler düzeyinde yürütülen bu çalışmanın amacı çerçevesinde belirlenen evren, UNCTAD veri tabanında yer alan ülkelerden oluşmaktadır. DYY verileri ise UNCTAD veri tabanından alınmıştır. Söz konusu veritabanı incelendiğinde, 
ülkelere gelen DYY verilerinin elde edildiği toplam 143 ülkenin mevcut olduğu görülmektedir. Evrenden örneklem seçimi konusunda çalışmanın amacı ve kısıtları dikkate alınarak kasıtlı örnekleme yöntemi kullanılmıştır. Buna göre çalışmanın bağımsız değişkenlerinin elde edildiği TSRE'nin kapsadığı 2007 2019 yılları referans alınarak söz konusu endeks kapsamında yer alan 114 ülke belirlenmiştir. Bu ülkelerin DYY verileri incelenerek araştırmaya dâhil edilen yılların herhangi birinde negatif DYY verisi olan ülkeler çıkarılmış ve geriye kalan 77 ülke çalışmanın örneklemini oluşturmaktadır. Bu ülkelerin genel olarak; gelişmiş, gelişmekte olan ve az gelişmiş ülkeleri içeren geniş bir coğrafi dağılımı temsil ettikleri görülmektedir.

Çalışmanın bağımsız değişkenlerini oluşturan destinasyon rekabetçiliği boyutları Dünya Ekonomik Forumu TSRE'den elde edilmiş̧ir. Bu endeks 2007 2009 yılları arasında, yıllık periyotta düzenli olarak her yıl yayınlanmış olup 2009 sonrasında iki yılda bir yayınlanmaya başlanmıştır. 2007, 2008, 2009, 2011, 2013, 2015, 2017 ve 2019 yıllarında yayınlanan TSRE'de toplam 140 ülke 4 ana faktör (Çevresel Faktörler, Turizm Politikalarının ve Koşullarının Etkinleştirilmesi, Altyapı, Doğal ve Kültürel Kaynaklar) altında sıralanmıştır. Çalı̧̧manın bağımsız değişkenini oluşturan DYY girişleri ile ilgili veriler TSRE'nin yayımlanma periyodu dikkate alınarak 2007-2019 yılları arasında 2'şer yıllık periyotları kapsamaktadır.

\section{B. Araştırmanın Yöntemi}

Araşıtırma kapsamında yer alan değişkenlerin tanımlayıcı istatistikleri ve korelasyon katsayıları Tablo 1'de özetlenmektedir. Değişkenler arasındaki korelasyonlar \%80 ve altında olduğundan çoklu doğrusal bağlantı sorunu bulunmamaktadır (Bryman and Cramer, 1992).

Tablo 1: Değişkenler arası korelasyonlar

\begin{tabular}{lccccccccr}
\hline & Ort. & ss. & $\min$ & $\max$ & $\mathbf{1}$ & $\mathbf{2}$ & $\mathbf{3}$ & $\mathbf{4}$ & $\mathbf{5}$ \\
\hline 1.DYY $(\ln )$ & 8,15 & 1,93 & 2,40 & 13,06 & 1 & & & & \\
\hline 2. Çevre & 4,50 & 0,82 & 2,75 & 6,22 & $0.49^{*}$ & 1 & & & \\
\hline 3.Politika & 4,50 & 0,41 & 3,30 & 5,72 & $0.10^{*}$ & $0.27^{*}$ & 1 & & \\
\hline 4. Altyap1 & 3,63 & 1,16 & 1,62 & 6,34 & $0.62^{*}$ & $0.78^{*}$ & $0.41^{*}$ & 1 & \\
\hline 5. Kaynaklar & 3,37 & 1,20 & 1,38 & 6,75 & $0.65^{*}$ & $0.30^{*}$ & $0.14^{*}$ & $0.53^{*}$ & 1 \\
\hline
\end{tabular}

Araştırmada hem zaman hem de birimlere göre analiz yapabilme imkanı sağlayan Panel veri analizi yöntemi kullanılmıştır. Test edilecek model aşağıdaki gibidir;

$$
\operatorname{lnfdi}_{i t}=\alpha+\beta_{1} \text { environ }_{i t}+\beta_{1} \text { ttpolicy }_{i t}+\beta_{1} \text { infra }_{i t}+\beta_{1} \text { resources }_{i t}+\varepsilon_{i t}
$$

Modelde, $\ln f d i_{i t} ;$ doğrudan yabancı sermaye yatırımının doğal logaritmasını, $\alpha$; sabit terimi, $\beta_{i}$; bağımsız değişken katsayılarını, $\varepsilon_{i t}$; hata terimini, environ ${ }_{i t}$; çevresel faktörleri, ttpolicy $_{i t}$; turizm politikalarının ve 
koşullarının etkinleştirilmesini, infra $i t$; altyapıyı ve resources $_{i t}$; doğal ve kültürel kaynakları ifade etmektedir.

Araştırmada öncelikle, Havuzlanmış, Sabit Etkiler ve Rassal Etkiler Modelleri arasından veri setine uygun model tespit edilmiştir (Tablo 2).

Tablo 2: Araştırmaya Uygun Modelin Tespiti İçin Yapılan Testler ve Sonuçları

\begin{tabular}{llll}
\hline Modeller & $\begin{array}{l}\text { Havuzlanmış }- \\
\text { Sabit Etkiler }\end{array}$ & $\begin{array}{l}\text { Havuzlanmış }- \\
\text { Rassal Etkiler }\end{array}$ & $\begin{array}{l}\text { Sabit Etkiler }- \\
\text { Rassal Etkiler }\end{array}$ \\
\hline Test & Chow & $\begin{array}{l}\text { Breusch ve Pagan LM } \\
\text { (Lagrangian Multiplier) }\end{array}$ & Hausman \\
\hline Sonuç & $\begin{array}{l}\mathrm{F}(76,535)=15,95 \\
\text { Prob }>\mathrm{F}=0,0000\end{array}$ & $\begin{array}{l}\text { chibar2(01):667,85 } \\
\text { Prob>chibar2=0,0000 }\end{array}$ & $\begin{array}{l}\text { chi2(4): 104,93 } \\
\text { Prob }>\text { chi2 }=0,0000\end{array}$ \\
\hline $\begin{array}{l}\text { Tercih } \\
\text { Edilen } \\
\text { Model }\end{array}$ & Sabit Etkiler & Rassal Etkiler & Sabit Etkiler \\
\hline
\end{tabular}

Havuzlanmış ve Sabit Etkiler modelleri arasındaki tercih için Chow (1960) homojenlik sınaması yapılmış ve birim etkili Sabit Etkiler modeli tercih edilmiştir. Havuzlanmış ve Rassal Etkiler modelleri arasındaki tercih için Breusch ve Pagan LM (1980) sınaması yapılmış ve birim etkili Rassal Etkiler modeli tercih edilmiştir. Sabit Etkiler ve Rassal Etkiler modelleri arasındaki tercih için Hausman (1978) sınaması yapılmış ve birim etkili Sabit Etkiler modelinin veri setimize en uygun model olduğu tespit edilmiştir.

Sabit Etkiler modelinin varsayımlarının sağlanması için Değişen Varyans, Otokorelasyon ve Yatay Kesit Bağımlılığı testleri yapılmış ve elde edilen sonuçlar Tablo 3’te açıklanmıştır.

Tablo 3: Sabit Etkiler Modelinin Varsayım Testleri ve Sonuçları

\begin{tabular}{|c|c|c|c|}
\hline Test & $\begin{array}{l}\text { Greene } \\
\text { Değiştirilmiş Wald }\end{array}$ & Baltagi Wu LBİ & Pesaran $\mathrm{CD}_{\mathrm{LM}}$ \\
\hline \multirow[t]{2}{*}{ Sonuç } & chi $2=26657,40$ & $\begin{array}{l}\text { Baltagi-Wu } \\
\mathrm{LBI}=1,8003775\end{array}$ & \\
\hline & Prob $>$ chi $2=0,0000$ & Prob $>F=0,0010$ & $\operatorname{Pr}=0,0000$ \\
\hline \multirow[t]{2}{*}{ Varsayım } & $\begin{array}{l}\text { Değişen Varyans } \\
\text { Sorunu }\end{array}$ & $\begin{array}{l}\text { Otokorelasyon } \\
\text { Sorunu }\end{array}$ & $\begin{array}{l}\text { Yatay Kesit } \\
\text { Bağımlılığ } 1\end{array}$ \\
\hline & VARDIR & VARDIR & VARDIR \\
\hline
\end{tabular}

Değiştirilmiş Wald testi yapılmış ve değişen varyans sorunu olduğu tespit edilmiştir. Baltagi Wu LBİ (Local Best Invariant) testi (Baltagi and Wu, 1999) yapılmış, elde edilen sonuç 2'den küçük olduğu için otokorelasyon sorununun varlığı tespit edilmiştir (Tatoğlu, 2020: 241). Modeldeki ülkelerin sayısının (77) analize dahil edilen yıllardan (8) fazla olması nedeniyle olduğundan Pesaran $\mathrm{CD}_{\mathrm{LM}}$ testi (Pesaran, 2004) yapılımış ve yatay kesit bağımlılı̆̆ının olduğu tespit edilmiştir.

Değişen varyans, otokorelasyon ve yatay kesit bağımlılığı sorunlarının giderilmesi için Driscoll-Kraay (1998) dirençli standart hataları kullanılmış 
(Tatoğlu, 2020: 335) ve elde edilen sonuçlar Tablo 4'te açıklanmıştır. Model, istatistiksel olarak anlamlı bulunmuş ve $\mathrm{H}_{1}$ hipotezi kabul edilmiştir. Bu durumda Dünya ekonomik forumu seyahat ve turizm rekabetçiliği endeksi ile doğrudan yabancı yatırımlar arasında anlamlı bir ilişki vardır denilebilir. Ancak, açıklayıcılık oranı (R-Kare within=0,0104) oldukça düşüktür.

Tablo 4: Panel Regresyon Bulguları

\begin{tabular}{|c|c|c|c|c|}
\hline DYY (ln) & Katsayı & Standart Hata ${ }^{\mathrm{a}}$ & $\mathrm{t}$ & $P>|t|$ \\
\hline Çevre & $-0,0351$ & 0,1306 & $-0,27$ & 0,789 \\
\hline Politika & $-0,1575$ & 0,1040 & $-1,52$ & 0,134 \\
\hline Altyap1 & 0,2322 & 0,1032 & 2,25 & 0,027 \\
\hline Kaynaklar & 0,0890 & 0,0351 & 2,54 & 0,013 \\
\hline Sabit & 7,8731 & 0,7423 & 10,61 & 0,000 \\
\hline \multicolumn{5}{|c|}{$R^{2} \quad 0,0104$} \\
\hline & & $\mathrm{F}=3,16$ & \multicolumn{2}{|c|}{ Prob $>F=0,0185$} \\
\hline
\end{tabular}

${ }^{a}$ Driscoll-Kraay dirençli standart hataları kullanılmıştır.

$\mathrm{H}_{1 \mathrm{a}}$ hipotezi reddedilmiştir (Prob $=0,789$ ). Çevresel faktörler ile doğrudan yabancı yatırımlar arasında anlamlı bir ilişki bulunamamıştır.

$\mathrm{H}_{1 \mathrm{~b}}$ hipotezi reddedilmiştir (Prob $=0,134$ ). Turizm politikalarının ve koşullarının etkinleştirilmesi ile doğrudan yabancı yatırımlar arasında anlamlı bir ilişki bulunamamıştır.

$\mathrm{H}_{1 \mathrm{c}}$ hipotezi kabul edilmiştir (Prob $=0,027$ ). Altyapı ile doğrudan yabancı yatırımlar arasında anlamlı ve pozitif yönlü bir ilişki vardır.

$\mathrm{H}_{1 \mathrm{~d}}$ hipotezi kabul edilmiştir (Prob = 0,013). Doğal ve Kültürel Kaynaklar ile doğrudan yabancı yatırımlar arasında anlamlı ve pozitif yönlü bir ilişki vardır.

\section{Sonuç ve Öneriler}

Ülkeler kalkınma seviyelerini arttırmak için yerel kaynaklarının yanında yabancı kaynaklara da ihtiyaç duymaktadırlar. Daha fazla DYY çeken ülkeler, daha hızlı bir şekilde büyümektedirler. Bu nedenle, ülkeler DYY çekmek için birbirleri ile rekabet etmektedirler. Finansal piyasalara gelen yabancı sermayenin çok hızlı ve kolay bir şekilde ülkeyi terk edebilme olasılığı nedeniyle DYY ülkeler açısından daha kalıcı yabancı kaynak olarak görülmektedir. Bu nedenle, DYY ülkelerin uzun vadeli ve sürdürülebilir büyümeleri için ciddi önem arz etmektedir. DYY'nin içerisinde turizm sektörüne yapılan yatırımlar da bulunmaktadır. Gelecek yıllarda dünya genelinde turizm sektöründen hizmet alacak kişilerin sayısının 1,8 milyara ulaşacağı tahmin edilmektedir (UNWTO, 2017). Böyle bir durumda turizm sektörüne yapılacak olan DYY'nin da artacağ1 öngörülebilmektedir.

Dünya Ekonomik Forumu, iki yılda bir TSRE açıklamaktadır. Bu endeks, ülkeleri destinasyon rekabetçilik güçlerine göre puanlandırarak sıralamaktadır. Bu çalışmada TSRE'nin 4 ana kriterinin DYY üzerindeki etkisini tespit etmek için panel veri analiz yapılmıştır. $\mathrm{Bu}$ analiz sonucunda çevresel faktörler ile turizm politikalarının ve koşullarının etkinleştirilmesi değişkeninin DYY üzerindeki etkisinin istatistiksel olarak anlamlı olmadığı tespit edilmiştir. Ev 
sahibi ülkenin kurumsal çevresinin, yabancı işletmenin yatırım kararında çok da etkili olmadığı sonucuna ulaşılmıştır. Ayrıca, altyapı ile doğal ve kültürel kaynaklar değişkenleri ile DYY arasındaki ilişki istatistiksel olarak anlamlı bulunmuş ve bu değişkenler DYY'yi pozitif olarak etkilemektedir. Bu bulgu Dunning'in Eklektik Paradigması çerçevesinde değerlendirildiğinde yabanc1 işletmeler için ev sahibi ülkenin altyapı olanaklarının geniş olması ve özellikle turizm için ayrıcalıklı bir öneme sahip olan doğal ve kültürel kaynaklara sahip olmasının söz konusu evsahibi ülkeye yatırım yapma kararı vermelerinde etkili olan bir konum avantajı olarak işlev gördüğü söylenebilmektedir.

Araştırmada ülkelere gelen toplam DYY bağımlı değişken olarak ele alınmış, sadece turizm sektörüne gelen DYY verilerine ulaşılamamıştır. Gelecek çalışmalarda sadece turizm sektörüne gelen DYY verilerinin elde edilebilme imkânı olması durumunda DYY ile TSRE arasında yapılacak analizlerin daha anlamlı sonuçlar verebileceği düşünülmektedir. Bu durum çalışmanın kısıtı olarak değerlendirilmektedir. Ayrıca, TSRE'nin alt kriterlerinin de çalışmaya dâhil edilmesi ile yapılacak araştırmalardan elde edilecek sonuçlar farklı analizler yapmaya imkân sağlayabilecektir.

\section{Kaynaklar}

Afşar, M. (2004). Doğrudan Yabancı Yatırımlar ve Bankacıllk Sektörü. Ege Akademik Bakış. 4(1), 85-101.

Asiedu, E. (2003). Foreign direct investment to Africa: The role of government policy, governance and political instability. Department of Economics, University of Kansas.

Aykut, D. \& Sayek, S. (2007). The Role of the Sectoral Composition of Foreign Direct Investment on Growth. Do Multinationals Feed Local Development and Growth? In Lucia Piscitello ve Grazia D. Santangelo (Ed.) 1. Edt. Elsevier: Oxford. 35-59.

Bahar, O. (2010). Turizm Sektörüne Sağlanan Doğrudan Yabancı Sermaye Yatırımlarının (DYSY) Ekonomik Büyüme Üzerine Olan Etkisi: Türkiye Örneği (1986-2006). Anatolia: Turizm Araştırmaları Dergisi, 21(1), 27-40.

Baltagi, H., Badi \& Ping X. Wu, (1999), Unequally Spaced Panel Data Regressions with Ar (1) Disturbances, Econometric Theory, 15(06), 814-823.

Bevan A. \& Estrin, S. (2000). The Determinants of Foreign Direct Investment in Transition Economies. William Davidson Institute Working Paper, 342.

Breusch, T.S. \& Pagan, A.R. (1980). The Lagrange multiplier test and its applications to model specification in econometrics. The review of economic studies, 47(1), 239-253.

Bryman, A., \& Cramer, D. (1992). Quantitative data analysis for social scientists. Estudios Geográficos, 53(207), 347.

Busse, M \& Hefeker C. (2005). Political Risk, Institutions and Foreign Direct Investment. Hamburg Institute of International Economics, Hamburg, Germany. 
Candemir, A. (2009). Doğrudan Yabancı Sermaye Yatırımlarını Etkileyen Faktörler. Ege Akademik Bakış, 9(2), 659-675.

Cheng, L. K., \& Kwan, Y. K. (2000). What are the determinants of the location of foreign direct investment? The Chinese experience. Journal of international economics, 51(2), 379-400.

Cheng, S, 2006, "The role of labor cost in the location choices of Japanese investors in China," Papers in Regional Science, 85(1), 121-138.

Chow, G. C. (1960). Tests of equality between sets of coefficients in two linear regressions. Econometrica: Journal of the Econometric Society, 28, 591-605.

Contractor, F. J. \& Kundu, S. K. (1995). Explaining Variation in The Degree of Internationalization Across Firms: The Case of Hotel Industry. Journal of International Management, 1, 87-123.

Dees, S. (1998). Foreign direct investment in China: determinants and effects. Economics of planning, 31(2-3), 175-194.

Di Maggio, P. J., \& Powell, W. W. (1983). The iron cage revisited: Institutional isomorphism and collective rationality in organizational fields. American sociological review, 147-160.

Dobrivojevic, G. (2013). Analysis of the Competitive Environment of Tourist Destinations Aiming at Attracting FDI by Applying Porter's Five Forces Model. British Journal of Economics, Management \& Trade. 3(4), 359-371.

DPT. (2000). Doğrudan Yabancı Sermaye Yatırımları. Özel İhtisas Komisyonu Raporu.

Driscoll, J. C. \& Kraay, A. C. (1998). Consistent covariance matrix estimation with spatially dependent panel data. Review of economics and statistics, 80(4), 549-560.

Dunning, J.H. (1980). Toward an eclectic theory of international production: some empirical tests. Journal of International Business Studies, 11(1), 9-31.

Dunning, J.H. (1988). The eclectic paradigm of international production: a restatement and some possible extensions. Journal of International Business Studies, 19(1), 1-31.

Dunning, J.H. (1993). Multinational Enterprises and the Global Economy. New York: Addison-Wesley.

Dunning, J.H. (2000). The eclectic paradigm as an envelope for economic and business theories of MNE activity. International business review, 9(2), 163190.

Dunning, J.H. (2001). The eclectic (OLI) paradigm of international production: past, present and future. International Journal of the Economics of Business, $8(2), 173-190$. 
Dunning, J.H. \& Lundan, S. M. (2008). Multinational Enterprises and the Global Economy. 2nd Edition. Edward Edgar Publishing Limited: UK

Dunning, J.H. \& Narula, R. (2004). Multinationals and Industrial Competitiveness: A New Agenda. Massachusetts, EUA.

Endo, K. (2006). Foreign Direct Investment in Tourism- flows and volumes, Tourism Management, 27, 600-614.

Erdal, F. \& Tatoglu, E. (2002). Locational determinants of foreign direct investment in an emerging market economy: evidence from Turkey. Multinational Business Review, 10(1), 21-27.

Fauzel, S., Seetenah, B. \& Sannasse, R. V. (2017). Analyzing The Impact of Tourism Foreign Direct Investment on Economic Growth: Evidence from a Small Island Developing State. Tourism Economics, 23(5), 1042-1055.

Fayos-Sola, E. \& Pedro Bueno, A. (2001) Tourism globalization and the competitive advantage of nations, Tourism in the age of Globalization. London and New York, Routledge.

Filatotchev, I., Strange, R., Piesse, J., \& Lien, Y-C. (2007). FDI by firms from newly industrialized economies in emerging markets: corporate governance, entry mode and location. Journal of International Business Studies, 38(4), 556-572.

Hausman, J.A. (1978). Specification tests in econometrics. Econometrica: Journal of the econometric society, 46(6), 1251-1271.

İlhan-Nas T., Okan T., Düzgün A. \& Çam H. (2020). Türkiye'den dişarıya yapılan DYY'ların giriş stratejilerinin belirleyicileri üzerine bir araştırma: uluslararasılaşma kuramları bakış açısı. Gümüşhane Üniversitesi Sosyal Bilimler Enstitüsü Elektronik Dergisi, 11(3), 592-614.

Johanson, J., \& Vahlne, J-E. (1977). The internationalization process of the firma model of knowledge development and increasing foreign market commitments. Journal of International Business Studies, 8(1), 23-32.

Johanson, J., \& Wiedersheim-Paul, F. (1975). The internationalization of the firm - four Swedish cases. The Journal of Management Studies, 12(3), 305-323.

Kar, M. \& Tatlısöz, F. (2008). Türkiye'de Doğrudan Yabancı Sermaye Hareketlerini Belirleyen Faktörlerin Ekonometrik Analizi. Kahramanmaraş Sütçü İmam Üniversitesi IIIBF Dergisi, 8(14), 436-458.

Karagöz, K. (2007). Türkiye'de Doğrudan Yabancı Yatırım Girişlerini Belirleyen Faktörler: 1970-2005. Journal of Yasar University. 2(8), 927-948.

Karoğlu, E. (2018). The Effect of Corruption Distance on Turkey's Inward Foreign Direct Investment. 2nd International Conference on New Approaches in Social Science and Humanities the Book of Proceedings and Abstracts, 130-131. 
Kepenek, Y. \& Yentürk, N. (2000). Türkiye Ekonomisi. 11. Basım. İstanbul Remzi Kitabevi.

Koçtürk, M. \& Eker, M. (2012). Dünya'da ve Türkiye'de Doğrudan Yabancı Sermaye Yatırımları ve Çok Uluslu Şirketlerin Gelişimi. Tarım Ekonomisi Dergisi, 18(1), 35-42.

Kundu, S. K. \& Contractor, F. J. (1999). Country Location Choices of Services Multinationals - An Empirical Study of The İnternational Hotel Sector. Journal of International Management, 5(4), 299-317.

Leuz, C., Lins, K.V. \& Warnock, F. E. (2010). Do Foreigner Invest Less in Poorly Governed Firms? Review of Financial Studies, 23(3), 3245-3285.

Mathews, J.A. (2002). Competitive advantages of the latecomer firm: a resourcebased account of industrial catch-up strategies. Asia Pacific Journal of Management, 19(4), 467-488.

Mathews, J.A. (2006). Dragon multinationals: new players in 21st century globalization. Asia Pacific Journal of Management, 23(1), 5-27.

Metaxas, T. (2010). Place Marketing, Place Branding and Foreign Direct Investments: Defining Their Relationship in The Frame of Local Economic Development Process. Place Branding and Public Diplomacy, 6(3), 228-243.

Morisset, J. (2000). 'Foreign Direct Investment in Africa: Policies also Matter'. Transnational Corporations, 9(2), 107-125.

Özcan, B. \& Arı, A. (2010). Doğrudan Yabanc1 Yatırımların Belirleyicileri Üzerine Bir Analiz: OECD Örneği. Istanbul Üniversitesi İktisat Fakültesi Ekonometri ve İstatistik Dergisi, 12, 65-88.

Peric J. \& Radic, M. N. (2015) Tourism Productivity and Tourism FDI in Croatia, Mediterranean Journal of Social Sciences, 6(5), 425-433.

Pesaran, M. H. (2004). “Genaral Diagnostic Test for Cross Section Dependence In Panels", Cambridge Working Papers in Economics, Vol. 0435, 1-41.

Ravinthirakumaran, K., Selvanathan, E. A., Selvanathan, S., \& Singh, T. (2015). Determinants of foreign direct investment in Sri Lanka. South Asia Economic Journal, 16(2), 233-256.

Rodrick, D., Subramanian, A., \& Trebbi, F. (2004). Institutions Rule: The Primacy of Institutions Over Geography and Integration in Economic Development. Journal of Economic Growth, 9(2), 131-165.

Rodriguez, A. R. (2002). Determining Factors in Entry Choice for International Expansion: The Case Of The Spanish Hotel Industry, Tourism Management, 23(6), 597-607.

Salleh, N. H. M., Othman, R. \& Sarmidi, T. (2011). An Analysis Of The Relationships Between Tourism Development And Foreign Direct Investment: An Empirical Study in Selected Majör Asian Countries. International Journal of Business and Social Science, 2(17), 250-257. 
Scott, W. R. (1995). Institutions and Organizations. Sage.

Singh, H. \& Jun, K. W. (1995). Some New Evidence On Determinants Of Foreign Direct Investment in Developing Countries. Policy Research Working Papers, World Bank.

Subbarao, S. P (2008). A study on Foreign Direct Investment (FDI) in Indian Tourism. Conference on Tourism in India - Challenges Ahead 15-17 Mayls 2008.107-113.

Surdu, I., Mellahi, K., \& Glaister, K. (2018). Emerging market multinationals' international equity-based entry mode strategies. International Marketing Review, 35(2), 342-359.

Tang, S., Selvanathan, E.A. \& Selvenathan, S. (2007). The Relationship Between Foreign Direct Investment and Tourism: Empirical Evidence From China. Tourism Economics, 13(1), 25-39.

Tatoglu, E., \& Glaister, K. W. (1998a). Determinants of foreign direct investment in Turkey. Thunderbird International Business Review, 40(3), 279-314.

Tatoglu, E., \& Glaister, K. W. (1998b). Western MNCs' FDI in Turkey: an analysis of location specific factors. Management International Review, 38(2), 133-159.

Tatoğlu, F.Y. (2020). "Panel Veri Ekonometrisi Stata Uygulamalı", Beta Yayınevi, Genişletilmiş 5. Baskı.

Tomohara, A. (2016). Japan's Tourism-Led Foreign Direct Investment Inflows: An Empirical Study. Economic Modelling, 52. 435-441.

UNCTAD, World Investment Report (2006): Incentives and Foreign Direct Investment, United Nation.

UNWTO. (2017). Tourism Highlights, 2017 edition.

Ussi, M. U., \& Wei, J. G. (2011). The Location determinants for hotel foreign direct investment (FDI) in Zanzibar. Management and Service Science, 8, 105-112.

WEF (2019), The Travel \& Tourism Competitiveness Report 2019

WTTC. (2018). Travel \& Tourism Economic Impact 2017 World.

https://unctad.org/

https://www.weforum.org/ 